\title{
SLC12A3 variants modulate LDL cholesterol levels in the Mongolian population
}

\author{
Caiyan $\mathrm{An}{ }^{1}$, Kejin Zhang ${ }^{2}$ and Xiulan $\mathrm{Su}^{1 *}$ (D)
}

\begin{abstract}
Background: Abnormalities in lipid metabolism are crucial factors in the pathogenesis of cardiovascular disease (CVD). Variants of many genes have been verified to confer risk for lipid metabolism abnormalities. However, the relationship between genetic variants of the NCC-encoding SLC12A3 gene and lipid metabolism in the Mongolian population remains unclear. In the present study, we aimed to elucidate the effects of SLC12A3 variants on Mongolian lipid metabolism, including total cholesterol (TCHO), triglycerides (TG), low-density lipoprotein cholesterol (LDL-c), and high-density lipoprotein cholesterol (HDL-c).
\end{abstract}

Methods: A randomly selected population of Mongolians $(n=331)$ from China underwent clinical testing. An ANOVA test, Kruskal-Wallis $H$ test (K-W test) and haplotype analysis were used to evaluate the association between the levels of lipids (TCHO, TG, LDL-C, and HDL-c) and polymorphisms in SLC12A3 loci.

Results: We identified three single nucleotide polymorphisms (SNPS) rs5803, rs2010501 and rs711746 in the SLC12A3 gene that were significantly associated with an individual's serum LDL-c level. Haplotypes combining these SNPs also showed the same trend (all $p$ values $<0.01$ ). Furthermore, the influence of SLC12A3 genetic polymorphisms on differences in individual serum LDL-c levels remained significant, even after we controlled gender, and demographic and other non-genetic factors.

Conclusion: These results suggest that variants of the SLC12A3 gene confer susceptibility to the abnormal serum LDL-C level in the Mongolian population.

Keywords: Lipid metabolism, Low-density lipoprotein cholesterol (LDL-c), SLC12A3, Mongolians, Haplotype

\section{Background}

Serum lipid and lipoprotein concentrations are tightly associated with cardiovascular disease (CVD), which is the major leading cause of death and disability worldwide [1]. Abnormalities in lipid metabolism, such as increased levels of triglycerides (TG) and low-density lipoprotein cholesterol(LDL-c), and decreased levels of high-density lipoprotein cholesterol(HDL-c), have been identified to be crucial factors to the pathogenesis of CVD [2, 3]. Many well-designed studies have clearly established LDL-c as the major target for lipidmodifying therapy [4] because elevated LDL-c is a major contributor to CVD $[5,6]$.

Serum lipid levels are also modulated by genetic $[7,8]$ and multiple environmental risk factors $[9,10]$ and their

\footnotetext{
* Correspondence: xlsu2014@163.com

${ }^{1}$ Clinical Research Center of the Affiliated Hospital, Inner Mongolia Medical

University, Hohhot 010050, Inner Mongolia, China

Full list of author information is available at the end of the article
}

interactions $[11,12]$. Approximately $50 \%$ of serum lipid abnormalities can be explained by genetic variants [13]. For instance, Chen et al. [14] proposed that there was a close relationship between the MTHFR gene and the longevity of a cohort in Bama, a well-known home of longevity in China, and that $\mathrm{T}$ allele carriers had a modestly unfavorable impact on lipid levels (i.e., higher LDL-c level) with a gender difference. Sone et al. [15] discovered that the genetic variants of the FADS gene are associated with LDL-c level in Japanese males, and Cuevas et al. [16] suggested the HMGCR rs17671591 polymorphism as a genetic marker of lower LDL-c after atorvastatin therapy in the Chilean population.

In addition to genetic predisposition, epidemiological risk factors also play crucial roles in the abnormalities of lipid profiles, including, 1) gender differences, a common feature in an individual's serum lipid levels, and 2) body mass index (BMI, weight in kilograms divided by 
height in square meters). Garcia-Palmieri et al. [17] stated that diet and relative weight could account for up to $6 \%$ of the variability in serum cholesterol levels. To be more specific, for every 1-kg decrease in body weight, TG decreased by $0.011 \mathrm{mmol} / \mathrm{L}$ and HDL-c increased by $0.011 \mathrm{mmol} / \mathrm{L}$ [18]; 3) Lifestyle (e.g., smoking, alcohol consumption, etc.) has also been shown to influence serum lipid levels. Rimm et al. [19] documented that consuming $30 \mathrm{~g}$ of ethanol per day increased the concentrations of HDL-c by $3.99 \mathrm{mg} / \mathrm{dL}$, and $\mathrm{TG}$ by $5.69 \mathrm{mg} / \mathrm{dL}$; Yin et al. [11, 20] also showed that BMI, cigarette smoking and alcohol consumption could interact with certain lipid-related gene variants to modify the serum lipid levels in BaiKu Yao and Han Chinese ethnic groups.

Mongolian is one of the ethnic groups in China with a high prevalence of hypertension and lipid abnormalities. Family aggregation of the diseases in Mongolians suggests that the genetic factor might play an important role in the etiology of these diseases in Mongolians. The genetic basis of lipid abnormality is complex; therefore, it is a huge challenge for us to certify those true susceptible genes/loci to lipid abnormality. Carrying out association studies in some population with different evolutionary history and linkage disequilbrium (LD), such as minor ethnic groups, may further narrow these regions to identify the causal gene(s) and is helpful for the identification of functional variants of complex diseases.

Our previous studies demonstrated the association of SLC12A3 gene variants with Mongolian hypertension [21-23] and meanwhile we also found that the levels of TC [21], TG [21-23] and LDL-c [21, 23] are significantly increased, whereas that of HDL-c [21] is slightly decreased in Mongolian hypertension when compared with Mongolian normotensives. Thus, it is possible that the genetic polymorphisms of $S L C 12 A 3$ might be associated with hypertension via modulating an individual's serum lipid levels. This possibility was tested on a randomly selected population of Mongolians $(n=331)$ from China and at the present study we aimed to clarify the association of SLC12A3 variants with lipid profiles and the mechanisms underlying lipid abnormality in Mongolians and provide the scientific basis for the prevention and treatment of this complex disease.

\section{Methods}

\section{Subjects}

We tested 331 unrelated, randomly selected adult residents $(59.81 \%$ female, mean age $=45 \pm 12.17$ years (range 20-70 years old)) in the Inner Mongolia Autonomous Region of China, including Dongwuzhumuqin County, Xianghuang County, and the city of Xilinhot. All subjects were of Mongolian ethnic origins. Written informed consents were obtained from all participants. The study was performed in accordance with the Declaration of Helsinki and was approved by the Ethical Committee of Affiliated Hospital of Inner Mongolia Medical University.

\section{Demographic information and serum lipid parameters}

Demographic variables collected in this study included age, gender, smoking status and drinking status. A smoker was defined as smoking at least one cigarette per day for at least 1 year, and smoking status was categorized into never (76.44\%) and current (20.24\%) subgroups. Alcohol consumption was defined as current status $(20.54 \%)$, consuming $50 \mathrm{~mL}$ or more alcohol per day for at least 1 year. Participants' heart rate, or pulse, was measured as the number heart beats per minute. Subjects' height and weight were measured, body mass index (BMI) was calculated as weight (kg) divided by the square of height $(\mathrm{m})$, and waist-hip ratio (WHR) was assessed by dividing waistline $(\mathrm{cm})$ by hipline $(\mathrm{cm})$. Normal weight, overweight, moderate obesity, and severe obesity were defined by BMI and WHR indexes according to $\mathrm{WHO}$ recommendations.

Blood samples were obtained from the antecubital vein after $\geq 8 \mathrm{~h}$ of fasting. Part of the collected samples were used to determine serum lipid levels and another part were transferred into a tube with anti-coagulate solution and used to extract deoxyribonucleic acid (DNA). To profile individuals' serum lipid status, four important parameters, TCHO, TG, HDL-c, and LDL-c were measured within $8 \mathrm{~h}$, using routine methods in the local hospital. Fasting blood glucose was tested using a Dollar general glucose meter (Dollar, Korea). Genomic DNA was isolated from peripheral blood leukocytes using an AxyPrep-96 DNA Extraction Kit (Axygen, Union City, CA, USA).

\section{Tag SNPs and genotyping}

To minimize the genotyping load while maximizing association information, the implementation of haplotypetagging SNP (tSNP) selection was performed using the HAPLOVIEW 4.2 software package, using the method described by Gabriel et al.[24]. Fifteen SNPs of the SLC12A3 gene were chosen from HCB_Asian population data in the HapMap SNP set (version 22) (http://hapmap.ncbi.nlm.nih.gov/) based on pairwise $r^{2} \geq 0.5$ and minor allele frequency $(\mathrm{MAF}) \geq 0.05$.

The genotyping was performed as described previously [22]. In brief, 1) the target DNA sequences were amplified using a multiplex PCR method in a final volume of $10 \mu \mathrm{l}$; 2) thermal cycling was performed for all SNPs loci in Gene Amp PCR system 9600 (PerkinElmer, Waltham, MA, USA); and 3) the fluorescent products of ligase detection reaction were differentiated by Applied 
Biosystems 3730 DNA Analyzer (Applied Biosystems, CA, USA). To verify the accuracy of the genotyping results for tagSNPs, we randomly sequenced 20 samples.

\section{Statistical analysis}

PASW statistics 18 (formerly SPSS Statistics; http:// www.spss.com.hk/statistics) was used to analyze the data. The Hardy-Weinberg equilibrium (HWE) testing was calculated using the Finetti method (https:// ihg.gsf.de/cgi-bin/hw/hwa2.pl), and the gender differences for alleles and genotypes' distributions were also evaluated. All variables were categorized by the median value in study sample and $t$-tests were performed to estimate the effects of non-genetic variables on individuals' serum lipid levels. A one-way analysis of variance (ANOVA) and LSD post hoc test were performed to examine the influence of each tagSNP on individual serum lipid status (including TCHO, TG, HDL-c and LDL-c). The non-parametric test, Kruskal-Wallis $H$ test (K-W test) was also used. Linkage condition and haplotypes construction of positive SNPs were estimated by UNPHASED software (version 3.0.13) [25]. More stringent criteria for positive tag $\mathrm{SNP}(\mathrm{s})$ was adopted: tag $\mathrm{SNP}(\mathrm{s})$ which demonstrated a significant association using both ANOVA and the K-W test were considered.

To partial out other non-genetic variables (i.e., age, gender, BMI, and WHR) that might have influences on the relationship between SNPs and individuals' serum lipid status, a multiple regression analysis was performed in which the genotype group served as one of the class variables. For the multiple linear regression analysis, we performed the following steps: (step 1) entering control variable(s) and (step 2) entering both variables and the genetic information. The statistical power analysis was referred to as $p<0.05$ for two-tailed tests.

\section{Results}

\section{Demographic characteristics and serum lipid levels}

The general characteristics of subjects and their relationship with individuals' serum lipid levels were presented in Table 1. Comparison tests found that serum lipid profiles were correlated with several environmental factors, including age, gender, alcohol consumption, cigarette smoking, blood glucose, BMI and WHR $(p<0.05-$ 0.001 ). Older subjects ( $>45$ years) showed a significantly higher serum level of TG than that of younger subjects ( $\leq 45$ years $)(1.98 \pm 2.42$ vs. $1.51 \pm 1.26, p<0.05)$. Men had higher serum levels of TCHO, TG and LDL-c than women (all $p \mathrm{~s}<0.01-0.001$ ). Smokers also had higher serum levels of LDL-c than never smokers $(3.52 \pm 1.37$, $p<0.01)$. Alcohol consumption also exhibited significantly higher serum levels of TCHO, TG and LDL-c than never drinkers (all $p$ values $<0.05-0.01$ ). The subjects with higher glucose levels in blood had extremely higher serum levels of TCHO, HDL-c, LDL-c (all $p$ values $<0.001)$, and higher levels of TG $(p<0.05)$ than those with normal glucose. Lower heart rate per minute also showed a weak influence on individuals' $\mathrm{TCHO}$ and HDL-c levels (all $p$ values $<0.05$ ). Over-weight and obesity (BMI $>25.2 \mathrm{~kg} / \mathrm{m}^{2}$, or WHR $\left.>0.88\right)$ often yielded significantly higher levels of TG and HDL-c (all $p$ values < 0.05-0.001), whereas normal BMI was associated with a significantly high HDL-c level $(p<0.001)$.

\section{Genotyping and distribution analysis}

Genotype frequencies of all 15 SNPs showed no significant deviations from Hardy - Weinberg equilibrium (WHE), except rs2289119 and rs7204044 $\left(X^{2}=3.92, p=\right.$ 0.048 , and $X^{2}=7.27, p=0.007$, respectively). And no gender difference distributions of alleles and genotypes frequency were found. The genotyping success rates for all SNPs were higher than 96.98\% (321/331).

\section{Genetic variants effects on TCHO, TG, HDL-c and LDL-c}

Table 2 presented data of the genetic variants of the SLC12A3 gene on individuals' serum lipid profile. Rs5803 polymorphisms showed a significant association with individuals' serum level of LDL-c $(F=3.881, p=$ 0.022 for ANOVA, and $X^{2}=7.378, p=0.025$ for K-W test), the $\mathrm{T}$ allele carriers had higher LDL-c levels than CC genotype carriers $(3.32 \pm 1.38 \mathrm{mmol} / \mathrm{L}$ vs. $2.93 \pm$ $1.25 \mathrm{mmol} / \mathrm{L}$ ). Both rs2010501 and rs711746 had a close association with individuals' serum TCHO and LDL-c levels (all $p \mathrm{~s}<0.01$ ). Interestingly, when dominant genetic models (carriers of rare allele vs. dominant allele homozygous) were performed for all SNPs, the results demonstrated the same trend.

To confirm the above analyses, we also derived the predicted probabilities of being single for different genotypes from the linear regression equation, after controlling other variables. Finally, the association between rs5803, rs2010501, rs711746 and individuals' serum level of LDL-c was found to still be significant, even with other variables controlled $(B=-0.044$, Error $S D=$ $0.018, t=-2.490, p=0.014$ for $r 55803, B=0.048$, Error $S D=0.018, t=2.653, p=0.009$ for $\operatorname{rs} 2010501$, and $B=$ 0.040 , Error $S D=0.017, \quad t=2.350, p=0.020$ for rs711746). The $\mathrm{T}$ allele of rs5803 had a negative association with individuals' elevated serum level of LDL-c, whereas the $\mathrm{T}$ allele of $\mathrm{rs} 2010501$ and A allele of rs711746 with a positive association. The genetic polymorphisms of three SNPs contributed more than 11.9\% variation of individual's serum LDL-c level difference ( $R^{2}$ change $>0.119$, and Sig. of $F$ change $<0.001$, for both SNPs). Additionally, individuals' levels of blood glucose were found to have an extremely significant effect (all $p$ s $<0.001$ ). 
Table 1 Effects of demographic, lifestyle characteristics and other non-genetic factors on individuals' serum lipid levels

\begin{tabular}{|c|c|c|c|c|c|}
\hline Variables $^{a}$ & $\mathrm{n}$ & $\mathrm{TCHO}(\mathrm{mmol} / \mathrm{L})$ & $\mathrm{TG}(\mathrm{mmol} / \mathrm{L})$ & $\mathrm{HDL}-\mathrm{C}(\mathrm{mmol} / \mathrm{L})$ & $\mathrm{LDL}-\mathrm{c}(\mathrm{mmol} / \mathrm{L})$ \\
\hline \multicolumn{6}{|l|}{ Age (years) } \\
\hline$\leq 45$ & 171 & $4.76 \pm 1.77$ & $1.51 \pm 1.26$ & $1.49 \pm 0.58$ & $3.01 \pm 1.32$ \\
\hline$>45$ & 160 & $5.08 \pm 2.06$ & $1.98 \pm 2.42^{*}$ & $1.43 \pm 0.55$ & $3.25 \pm 1.33$ \\
\hline \multicolumn{6}{|l|}{ Sex } \\
\hline Male & 139 & $5.17 \pm 1.89^{* * *}$ & $2.00 \pm 2.00^{* *}$ & $1.45 \pm 0.58$ & $3.34 \pm 1.34^{* *}$ \\
\hline Female & 192 & $4.67 \pm 1.71$ & $1.58 \pm 1.36$ & $1.45 \pm 0.47$ & $2.98 \pm 1.28$ \\
\hline \multicolumn{6}{|l|}{ Smoker } \\
\hline Never & 253 & $4.85 \pm 1.92$ & $1.68 \pm 2.03$ & $1.47 \pm 0.54$ & $3.05 \pm 1.30$ \\
\hline Smoker & 67 & $5.31 \pm 1.96$ & $1.95 \pm 1.49$ & $1.47 \pm 0.66$ & $3.52 \pm 1.37^{* *}$ \\
\hline Unknown & 11 & - & - & - & - \\
\hline \multicolumn{6}{|l|}{ Drink } \\
\hline Never & 241 & $4.75 \pm 1.76$ & $1.59 \pm 1.43$ & $1.44 \pm 0.53$ & $3.03 \pm 1.30$ \\
\hline Drinker & 68 & $5.63 \pm 2.44^{* *}$ & $2.39 \pm 3.17^{* *}$ & $1.55 \pm 0.74$ & $3.54 \pm 1.44^{*}$ \\
\hline Unknown & 22 & - & - & - & - \\
\hline \multicolumn{6}{|c|}{ Blood_G (mg/ml) } \\
\hline$\leq 5.7$ & 160 & $4.38 \pm 1.71$ & $1.50 \pm 2.10$ & $1.32 \pm 0.47$ & $2.79 \pm 1.16$ \\
\hline$>5.7$ & 147 & $5.47 \pm 2.00^{* * *}$ & $1.99 \pm 1.67^{*}$ & $1.61 \pm 0.65^{* * *}$ & $3.44 \pm 1.39^{* * *}$ \\
\hline Unknown & 24 & - & - & - & - \\
\hline \multicolumn{6}{|c|}{ Heart_R $\left(\min ^{-1}\right)$} \\
\hline$\leq 76$ & 143 & $5.28 \pm 2.11^{*}$ & $1.85 \pm 2.25$ & $1.58 \pm 0.65^{*}$ & $3.30 \pm 1.37$ \\
\hline$>76$ & 122 & $4.75 \pm 1.89$ & $1.72 \pm 1.65$ & $1.41 \pm 0.54$ & $3.07 \pm 1.32$ \\
\hline Unknown & 66 & - & - & - & - \\
\hline \multicolumn{6}{|l|}{$\mathrm{BMI}\left(\mathrm{kg} / \mathrm{m}^{2}\right)$} \\
\hline$\leq 24.44$ & 166 & $4.84 \pm 1.95$ & $1.40 \pm 1.20$ & $1.60 \pm 0.63^{* * *}$ & $2.91 \pm 1.35$ \\
\hline$>24.44$ & 162 & $4.97 \pm 1.91$ & $2.07 \pm 2.39^{* *}$ & $1.32 \pm 0.47$ & $3.33 \pm 1.27^{* *}$ \\
\hline Unknown & 3 & - & - & - & - \\
\hline \multicolumn{6}{|l|}{ WHR } \\
\hline$\leq 0.87$ & 132 & $4.82 \pm 2.07$ & $1.40 \pm 1.20$ & $1.54 \pm 0.68$ & $3.00 \pm 1.35$ \\
\hline$>0.87$ & 128 & $5.23 \pm 2.00$ & $2.27 \pm 2.53^{* * *}$ & $1.42 \pm 0.54$ & $3.36 \pm 1.36^{*}$ \\
\hline Unknown & 71 & - & - & - & - \\
\hline
\end{tabular}

*** $p$ value $<0.001 ;{ }^{* *} p$ value $<0.01 ;{ }^{*} p$ value $<0.05$

Abbreviation $B M I$ body mass index, WHR waist-hip ratio, Blood G fasting blood glucose in serum, Heart $R$ heart rate per minute, $T C H O$ total cholesterol (mmol/L), TG triglycerides ( $\mathrm{mmol} / \mathrm{L}), H D L-C$ high-density lipoprotein cholesterol ( $\mathrm{mmol} / \mathrm{L}), L D L-C$ low-density lipoprotein cholesterol (mmol/L)

all variables were categorized by the median value in study sample

\section{Haplotype analysis for positive SNPs}

The linkage disequilibrium among the three positive SNPs was estimated by UNPHASED software, and a strong linkage disequilibrium between rs2010501 and rs711746 $\left(D^{\prime}=0.97, r^{2}=0.44\right)$ was observed. We constructed three sets of haplotypes. Two were derived from various combinations of two SNPs (two window size), and one was derived from a combination of all three SNPs (three window size). Three sets of haplotypes displayed significant additive genetic influences on individual's serum LDL-c levels in both two and three windows analyses (all global $p$ values $<0.001$ ). Several individual haplotypes, constructed by two or three SNP sites, demonstrated significant genetic effects on individuals' serum LDL-c levels, compared with the first haplotypes (all $p$ values $<0.05-0.001$ ) (Table 3 ).

\section{Discussion}

In this study, we investigated the influence of genetic polymorphisms in the SLC12A3 gene on human serum lipid levels (TCHO, TG, HDL-c and LDL-c), within a randomly selected Mongolian cohort in China. Our data demonstrated that three SNPs, rs5803, rs2010501 and rs711746 of 15 tag SNPs in the SLC12A3 gene were significantly associated with individuals' serum levels of LDL-c. Haplotypes combining with these SNPs also 
Table 2 Effects of SNPs on individuals' serum lipid levels

\begin{tabular}{|c|c|c|c|c|c|c|c|c|}
\hline \multirow[t]{2}{*}{$\mathrm{SNPs}^{a}$} & \multirow[t]{2}{*}{ Variables } & \multicolumn{3}{|c|}{ Genotypes/Mean (SD) } & \multicolumn{2}{|c|}{ ANOVA } & \multicolumn{2}{|l|}{$\mathrm{K}-\mathrm{W}$} \\
\hline & & & & & $\bar{F}$ & $p^{b}$ & $\overline{C h i^{2}}$ & $p^{b}$ \\
\hline \multirow[t]{5}{*}{ rs5803 } & & TT(25) & TC(126) & CC(177) & & & & \\
\hline & $\mathrm{TCHO}$ & $4.67 \pm 1.80$ & $5.21 \pm 1.93$ & $4.72 \pm 1.93$ & 2.591 & 0.076 & 6.536 & 0.038 \\
\hline & TG & $1.59 \pm 1.41$ & $1.77 \pm 1.48$ & $1.72 \pm 2.25$ & 0.098 & 0.907 & 4.247 & 0.120 \\
\hline & HDL-C & $1.49 \pm 0.60$ & $1.53 \pm 0.57$ & $1.42 \pm 0.55$ & 1.470 & 0.231 & 4.256 & 0.119 \\
\hline & LDL-C & $3.10 \pm 1.41$ & $3.36 \pm 1.38$ & $2.93 \pm 1.25$ & 3.881 & 0.022 & 7.378 & 0.025 \\
\hline \multirow[t]{5}{*}{ rs2010501 } & & $C C(16)$ & CT(110) & ТТ(195) & & & & \\
\hline & $\mathrm{TCHO}$ & $4.07 \pm 1.28$ & $4.70 \pm 1.97$ & $5.12 \pm 1.94$ & 3.390 & 0.035 & 7.014 & 0.030 \\
\hline & TG & $1.07 \pm 0.66$ & $1.64 \pm 2.51$ & $1.86 \pm 1.62$ & 1.492 & 0.227 & 13.604 & 0.001 \\
\hline & HDL-C & $1.35 \pm 0.54$ & $1.45 \pm 0.59$ & $1.50 \pm 0.56$ & 0.620 & 0.538 & 1.690 & 0.430 \\
\hline & LDL-C & $2.49 \pm 0.86$ & $2.87 \pm 1.28$ & $3.31 \pm 1.37$ & 5.868 & 0.003 & 11.173 & 0.004 \\
\hline \multirow[t]{5}{*}{ rs711746 } & & GG(48) & GA(148) & $\mathrm{AA}(125)$ & & & & \\
\hline & $\mathrm{TCHO}$ & $4.14 \pm 1.17$ & $5.00 \pm 2.01$ & $5.14 \pm 2.04$ & 4.910 & 0.008 & 7.553 & 0.023 \\
\hline & TG & $1.18 \pm 0.48$ & $1.83 \pm 2.38$ & $1.87 \pm 1.61$ & 2.444 & 0.088 & 11.284 & 0.004 \\
\hline & $\mathrm{HDL}-\mathrm{C}$ & $1.37 \pm 0.48$ & $1.49 \pm 0.59$ & $1.50 \pm 0.57$ & 1.020 & 0.362 & 2.177 & 0.337 \\
\hline & LDL-C & $2.55 \pm 0.85$ & $3.10 \pm 1.35$ & $3.35 \pm 1.42$ & 6.333 & 0.002 & 9.911 & 0.007 \\
\hline
\end{tabular}

Abbreviation: TCHO total cholesterol (mmol/L), TG triglyceride ( $\mathrm{mmol} / \mathrm{L}), H D L-c$ high-density lipoprotein cholesterol (mmol/L), $L D L-c$ low-density lipoprotein cholesterol (mmol/L), ANOVA one-way analysis of variance, $K-W$ Kruskal-Wallis $H$ test

${ }^{a}$ SNPs, at least one positive association between individuals' serum levels presented, were shown analyzed by both ANOVA and K-W tests

${ }^{\mathrm{b}}$ Bold type denotes $p<0.05$

showed the same trend. Furthermore, the influence of SLC12A3 genetic polymorphisms on the differences observed in individual serum LDL-c levels remained significant, even after we controlled demographic, gender and other non-genetic factors. To the best of our knowledge, this study is the first to demonstrate the influence of genetic variants in $S L C 12 A 3$ on human serum level of LDL-c.
LDL-c plays a pivotal role in CVD, while the association between elevated serum LDL-c level and hypertension remains unclear [26-28]. We observed an elevated serum LDL-c level in hypertensive patients [21, 23] when we investigated the association between genetic variants of SLC12A3 and hypertensive patients in Mongolians in China. The results from this randomly selected Mongolian sample were consistent with our

Table 3 Effects of haplotypes constructed by three positive SNPs on LDL-c levels

\begin{tabular}{|c|c|c|c|c|c|c|c|}
\hline Haplotypes $^{\text {a }}$ & Frequency (\%) & AddVal & 95\%Lo & $95 \% \mathrm{Hi}$ & Chisq & $p^{b}$ & Global $p^{\text {b }}$ \\
\hline & \multicolumn{7}{|c|}{ rs5803(T/C)-rs2010501(C/T) } \\
\hline $\mathrm{T}-\mathrm{T}$ & 22.43 & -0.044 & -0.042 & 0.335 & 4.927 & 0.026 & $2.23 e-4$ \\
\hline$C-C$ & 18.65 & -0.448 & -0.852 & -0.043 & 14.03 & $1.80 \mathrm{e}-4$ & \\
\hline \multirow[t]{2}{*}{$C-T$} & 55.25 & -0.105 & -0.453 & 0.243 & 1.002 & 0.317 & \\
\hline & \multicolumn{7}{|c|}{ rs2010501(C/T)-rs711746(G/A) } \\
\hline$C-G$ & 21.81 & - & - & - & 10.56 & $1.15 \mathrm{e}-3$ & $7.68 \mathrm{e}-4$ \\
\hline $\mathrm{T}-\mathrm{G}$ & 16.16 & 0.145 & -0.065 & 0.355 & 0.734 & 0.391 & \\
\hline \multirow[t]{2}{*}{ T-A } & 61.65 & 0.291 & 0.128 & 0.453 & 12.56 & $3.95 \mathrm{e}-4$ & \\
\hline & \multicolumn{7}{|c|}{ rs5803(T/C)-rs2010501(C/T)-rs711746(G/A) } \\
\hline T-T-A & 21.90 & -0.050 & -0.502 & 0.402 & 4.521 & 0.033 & $5.76 \mathrm{e}-4$ \\
\hline$C-C-G$ & 18.61 & -0.426 & -0.898 & 0.045 & 12.43 & $4.22 \mathrm{e}-4$ & \\
\hline C-T-G & 15.40 & -0.224 & -0.627 & 0.180 & 0.967 & 0.325 & \\
\hline C-T-A & 39.52 & -0.062 & -0.509 & 0.386 & 3.035 & 0.812 & \\
\hline
\end{tabular}

Abbreviation: Fre. is the frequencies of risk haplotypes, AddVal the estimated additive genetic value relative to the reference haplotype, $95 \%$ Lo $95 \%$ lower confidence limit for the additive value, $95 \% \mathrm{Hi} 95 \%$ upper confidence limit for the additive value

${ }^{a}$ The haplotypes frequencies $<0.05$ were excluded in global $p$-value calculation

${ }^{\mathrm{b}}$ Bold type denotes $p<0.05$ 
hypothesis that $S L C 12 A 3$ polymorphisms may modulate serum LDL-c level and represent a close relationship with hypertensive patients that have been reported previously $[22,23]$. Two SNPs (rs5803 and rs711746), which were reportedly associated with hypertension in casecontrol and family-based association studies, also showed significant influences on individuals' serum LDL-c level in the general Mongolian population. Collectively, these results demonstrated the important modulation effect of SLC13A gene on human serum LDL-c levels and their observed association with hypertension.

Demographic and lifestyle characteristics also showed a close relation with serum LDL-c levels, in addition to its genetic association. In the present population, several non-genetic variables, including gender, smoking status, alcohol consumption, fasting blood glucose, BMI and WHR, all contributed to differences in individuals' serum levels of LDL-c (Table 2). Meanwhile, gender difference may play an important role and should be considered further in future experiments. Lifestyle factors, including smoking status and alcohol consumption revealed an extreme difference between males and females. Males also demonstrated higher BMI and WHR indexes than females (data not shown). However, when we used linear regression analysis to estimate each variable's influence on individuals' LDL-c level, the impact of blood glucose concentration on LDL-c was observed, whereas the influence from other variables disappeared, except for the three genetic variants of SLC12A3. Hsu and Fava et al. $[29,30]$ also suspected that $S L C 12 A 3$ polymorphisms might regulate individuals' blood pressure via affecting their fasting plasma glucose concentrations.

One should be cautious when interpreting these findings given the following limitations. We examined the influence of genetic polymorphisms in the SLC12A3 gene on human LDL-c level status within a specific population. The high prevalence of hypertension is a serious health problem among Mongolian people [31], as CVD is a primary cause of morbidity and mortality [32]. Genetic influences of the SLC12A3 gene on LDL-c levels were revealed in this population. Second, the limited sample size should also be carefully noted, despite the statistical power analyses showing a satisfied estimation value. For some rare homozygous alleles, the sample size still seemed insufficient, especially when we partialed out subjects with missing variables. Third, several characteristics and lifestyle information were included in this study. These characteristics are susceptible to change, and it is not clear whether the association between the $S L C 12 A 3$ and LDL-c level would still hold. It may be the case that under certain circumstances, the genetic contribution to LDL-c level could be overshadowed by other factors. In addition, to avoid false association a double- measure was performed in our study, that is, the association between polymorphisms of SLC12A3 and lipid metabolism will be considered, only when both the parametric (ANOVA) and non-parametric (KW) analyses results were supportive and consistent. However, we couldn't rule out the impact of $S L C 12 A 3$ on individual's TCHO and TG levels, although it did not show a consistent correlation, completely.

\section{Conclusion}

Our results concluded that variants of the SLC12A3 gene confer susceptibility to the abnormal serum LDL-c levels in the Mongolian population.

\section{Abbreviations \\ ANOVA: One-way analysis of variance; BMI: Body mass index; CVD: Cardiovascular disease; HDL-C: High-density lipoprotein cholesterol; K-W: Kruskal-Wallis H test; LDL-C: Low-density lipoprotein cholesterol; MAF: Minor allele frequency; TCHO: Total cholesterol; TG: Triglycerides; WHR: waist-hip ratio}

\section{Acknowledgments}

We are grateful to all participants in this study.

\section{Funding}

This work was supported by the National Natural Science Foundation of China (No.81260058).

\section{Availability of data and materials}

All data generated or analyzed during this study are included in this published article.

\section{Authors' contributions}

$\mathrm{XL}$ Su conceived and designed the experiments. CY An carried out the experiments and wrote the paper. KJ Zhang analyzed the data. All authors read and approved the final manuscript.

\section{Competing interests}

The authors declare that they have no competing interest.

\section{Consent for publication}

Not applicable.

\section{Ethics approval and consent to participate}

Written informed consent was obtained from all participants. The study was performed in accordance with the Declaration of Helsinki and was approved by the Ethical Committee of Affiliated Hospital of Inner Mongolia Medical University.

\section{Author details \\ ${ }^{1}$ Clinical Research Center of the Affiliated Hospital, Inner Mongolia Medical University, Hohhot 010050, Inner Mongolia, China. Key Laboratory of Resource Biology and Biotechnology in Western China (Ministry of Education), College of Life Science, Institute of Population and Health, Northwest University, Xi'an, China.}

Received: 23 August 2016 Accepted: 11 January 2017 Published online: 06 February 2017

\footnotetext{
References

1. Mathers CD, Boerma T, Ma FD. Global and regional causes of death. Br Med Bull. 2009;92:7-32.

2. Castelli WP, Anderson K, Wilson PW, Levy D. Lipids and risk of coronary heart disease. The Framingham Study. Ann Epidemiol. 1992;2:23-8.

3. Matsuzawa Y. Significance of hypertriglyceridemia in the occurrence of ischemic heart disease. J Atheroscler Thromb. 1995;2 Suppl 1:S26-8.
} 
4. Ballantyne $\mathrm{CM}$, Davidson MH, Macdougall DE, Bays HE, Dicarlo LA, Rosenberg NL, et al. Efficacy and safety of a novel dual modulator of adenosine triphosphate-citrate lyase and adenosine monophosphateactivated protein kinase in patients with hypercholesterolemia: results of a multicenter, randomized, double-blind, placebo-controlled, parallel-group trial. J Am Coll Cardiol. 2013;62:1154-62.

5. Hartiala O, Magnussen CG, Kajander S, Knuuti J, Ukkonen H, Saraste A, et al. Adolescence risk factors are predictive of coronary artery calcification at middle age: the cardiovascular risk in young Finns study. J Am Coll Cardiol. 2012;60:1364-70.

6. Brautbar A, Ballantyne CM. Pharmacological strategies for lowering LDL cholesterol: statins and beyond. Nat Rev Cardiol. 2011;8:253-65.

7. Teslovich TM, Musunuru K, Smith AV, Edmondson AC, Stylianou IM, Koseki $M$, et al. Biological, clinical and population relevance of 95 loci for blood lipids. Nature. 2010;466:707-13.

8. Kathiresan S, Willer CJ, Peloso GM, Demissie S, Musunuru K, Schadt EE, et al. Common variants at 30 loci contribute to polygenic dyslipidemia. Nat Genet. 2009;41:56-65.

9. Hegsted DM, Ausman LM, Johnson JA, Dallal GE. Dietary fat and serum lipids: an evaluation of the experimental data. Am J Clin Nutr. 1993;57:875-83.

10. Ruixing $Y$, Yuming $C$, Shangling $P$, Fengping $H$, Tangwei $L$, Dezhai $Y$, et al. Effects of demographic, dietary and other lifestyle factors on the prevalence of hyperlipidemia in Guangxi Hei Yi Zhuang and Han populations. Eur J Cardiovasc Prev Rehabil. 2006;13:977-84

11. Yin RX, Wu DF, Miao L, Aung LH, Cao XL, Yan TT, et al. Several genetic polymorphisms interact with overweight/obesity to influence serum lipid levels. Cardiovasc Diabetol. 2012;11:123.

12. Miao L, Yin RX, Hu XJ, Wu DF, Cao XL, Li Q, et al. Association of rs2072183 SNP and serum lipid levels in the Mulao and Han populations. Lipids Health Dis. 2012;11:61.

13. Heller DA, de Faire U, Pedersen NL, Dahlen G, McClearn GE. Genetic and environmental influences on serum lipid levels in twins. N Engl J Med. 1993; 328:1150-6.

14. Chen NY, Liu CW, Du LL, Xiao LP, Ge L, Wang YY, et al. Enrichment of MTHFR $677 \mathrm{~T}$ in a Chinese long-lived cohort and its association with lipid modulation. Lipids Health Dis. 2014;13:104

15. Sone Y, Kido T, Ainuki T, Sonoda M, Ichi I, Kodama S, et al. Genetic variants of the fatty acid desaturase gene cluster are associated with plasma LDL cholesterol levels in Japanese males. J Nutr Sci Vitaminol (Tokyo). 2013;59: 325-35.

16. Cuevas A. HMGCR rs17671591 SNP Determines Lower Plasma LDL-C after Atorvastatin Therapy in Chilean Individuals. Basic Clin Pharmacol Toxicol. 2016;118:292-7.

17. Garcia-Palmieri MR, Tillotson J, Cordero E, Costas Jr R, Sorlie P, Gordon T, et al. Nutrient intake and serum lipids in urban and rural Puerto Rican men. Am J Clin Nutr. 1977;30:2092-100.

18. Yu-Poth S, Zhao G, Etherton T, Naglak M, Jonnalagadda S, Kris-Etherton PM. Effects of the National Cholesterol Education Program's Step I and Step II dietary intervention programs on cardiovascular disease risk factors: a metaanalysis. Am J Clin Nutr. 1999;69:632-46.

19. Rimm EB, Williams P. Fosher K, Criqui M, Stampfer MJ. Moderate alcohol intake and lower risk of coronary heart disease: meta-analysis of effects on lipids and haemostatic factors. BMJ. 1999;319:1523-8.

20. Yin RX, Wu DF, Miao L, Htet Aung LH, Cao XL, Yan $\pi$, et al. Interactions of several single nucleotide polymorphisms and high body mass index on serum lipid traits. Biofactors. 2013;39:315-25.

21. Chang PY, Zhao LG, Su XL. Association of TSC gene variants and hypertension in Mongolian and Han populations. Genet Mol Res. 2011;10: 902-9.

22. Liang JQ, Xi YG, An CY, Su XL. Association of variants in renal salt reabsorption-related gene SLC12A3 with essential hypertension in a Mongolian population. Genet Mol Res. 2015;14:10026-36.

23. An C, Liang J, Zhang K, Su X. Polymorphisms in the SLC12A3 Gene Encoding Sodium-Chloride Cotransporter are Associated with Hypertension: A Family-Based Study in the Mongolian Population. Kidney Blood Press Res. 2016;41:18-28

24. Gabriel SB, Schaffner SF, Nguyen H, Moore JM, Roy J, Blumenstiel B, et al. The structure of haplotype blocks in the human genome. Science. 2002;296: 2225-9

25. Dudbridge F. Likelihood-based association analysis for nuclear families and unrelated subjects with missing genotype data. Hum Hered. 2008;66:87-98.
26. Otsuka T, Takada H, Nishiyama Y, Kodani E, Saiki Y, Kato K, et al. Dyslipidemia and the risk of developing hypertension in a working-age male population. J Am Heart Assoc. 2016;4:e003053.

27. Takiwaki M, Tomoda F, Koike T, Taki T, Inoue H, Kigawa M, et al. Increased levels of small dense low-density lipoprotein cholesterol associated with hemorheological abnormalities in untreated, early-stage essential hypertensives. Hypertens Res. 2014;37:1008-13.

28. Salonen JT, Salonen R. Association of serum low density lipoprotein cholesterol, smoking and hypertension with different manifestations of atherosclerosis. Int J Epidemiol. 1990;19:911-7.

29. Hsu YJ, Yang SS, Chu NF, Sytwu HK, Cheng CJ, Lin SH. Heterozygous mutations of the sodium chloride cotransporter in Chinese children: prevalence and association with blood pressure. Nephrol Dial Transplant. 2009;24:1170-5.

30. Fava C, Montagnana M, Rosberg L, Burri P, Almgren $P$, Jonsson A, et al. Subjects heterozygous for genetic loss of function of the thiazide-sensitive cotransporter have reduced blood pressure. Hum Mol Genet. 2008;17:413-8.

31. Demaio AR, Otgontuya D, de Courten M, Bygbjerg IC, Enkhtuya P, Meyrowitsch DW, et al. Hypertension and hypertension-related disease in mongolia; findings of a national knowledge, attitudes and practices study. BMC Public Health. 2013;13:194

32. Enkh-Oyun T, Kotani K, Davaalkham D, Uehara R, Sadakane A, Aoyama Y, et al. Hypertension in Mongolia: an overview. Ethn Dis. 2013;23:363-8.

\section{Submit your next manuscript to BioMed Central and we will help you at every step:}

- We accept pre-submission inquiries

- Our selector tool helps you to find the most relevant journal

- We provide round the clock customer support

- Convenient online submission

- Thorough peer review

- Inclusion in PubMed and all major indexing services

- Maximum visibility for your research

Submit your manuscript at www.biomedcentral.com/submit 